\title{
Piezogravimetric investigation of heterocyclic compounds as potential inhibitors against copper corrosion in acidic media
}

\author{
A. Shaban, ${ }^{1 *}$ Gy. Vastag $^{2}$ and L. Nyikos ${ }^{1}$ \\ ${ }^{1}$ Functional Interfaces Group, Institute of Materials and Environmental Chemistry, \\ Research Centre for Natural Sciences, H. A. S., 1117 Budapest, Magyar tudósok körútja 2 \\ ${ }^{2}$ University of Novi Sad, Faculty of Sciences, Serbia \\ *E-mail:Shaban.Abdul@ttk.mta.hu
}

\begin{abstract}
Corrosion and inhibition processes can be followed by different in-situ methods at a nanometer scale. In this contribution, the corrosion breakdown potentials and inhibition efficiencies were evaluated using the electrochemical quartz crystal nanobalance (EQCN) technique, by recording linear potential scan for voltammetric $(i-E)$ and piezogravimetric $(m-E)$ characteristics. The effectiveness of thiazole derivatives, in an aggressive solution of $0.1 \mathrm{M} \mathrm{Na}_{2} \mathrm{SO}_{4}$, on the value of the breakdown potential of the copper electrode, was investigated. The investigated thiazole derivatives are: 5-benzylidene-2,4-dioxo tetrahydro1,3-thiazole (5-BDT) 5-(4'-isopropylbenzylidene)-2,4-dioxotetrahydro-1,3-thiazole (5IPBDT), 5-(3'-thenylidene)-2,4-dioxotetrahydro-1,3-thiazole (5-TDT) and 5-(3',4'dimetoxybenzylidene)-2,4-dioxotetrahydro-1,3-thiazole (5-MBDT). The inhibitor effectiveness was monitored and corrosion rates were determined. Previously found effects for some of the thiazole derivatives were confirmed. The most effective, among the tested thiazole derivatives against copper corrosion, was 5-IPBDT, due to the presence of the isopropyl functional group.
\end{abstract}

Key words: copper; copper corrosion; corrosion inhibitors; thiazole derivatives; EQCM; corrosion breakdown potential.

Received: July 28, 2015. Published: October 6, 2015.

doi: $\underline{10.17675 / 2305-6894-2015-4-4-3}$

\section{Introduction}

Copper and its alloys find great field of applications in modern industries. Copper is a relatively noble metal, however, it is susceptible to corrosion by acids and strong alkaline solutions, especially in the presence of oxygen or oxidants [1]. In the $\mathrm{pH}$ range between 2 and 5 the dissolution of $\mathrm{Cu}$ is relatively rapid and the formation of a stable surface oxide layer, which can passivate metal surfaces, is impossible. Copper can only be passivated by forming an oxide surface layer in weak acid or alkaline solutions. The behavior of copper and its alloys in acidic media is extensively investigated and several schemes have been presented for the dissolution process [1-6].

The application of corrosion inhibitors in such conditions becomes a necessity. The possibilities of the copper corrosion prevention, by the application of corrosion inhibitors, have been investigated using several methods [7]. Many types of inhibitors were 
investigated and among them are organic compounds and their derivatives such as azoles [7-15].

It is a well-known fact that organic compounds which contain polar groups including nitrogen, sulfur, and oxygen, and heterocyclic compounds with polar functional groups and conjugated double bonds have shown excellent inhibition properties against copper corrosion $[6,16-18]$. Their inhibition characters are attributed to their adsorption on the metal surface [16]. Among the tested organic compounds, against $\mathrm{Cu}$ corrosion, azoles showed efficient properties as a potential corrosion inhibitor for copper and its alloys in different environments [19, 20].

Some organic compounds form protective layers on the metal surface. Heterocyclic compound such as thiazole [21], benzotriazole [5, 22-23], tetrazole [24], triazole [2, 25], imidazole [26] and their derivatives, are among the inhibitors investigated for applications to prevent the corrosion of copper and its alloys in aqueous solutions.

Thiazoles are members of the azoles heterocycles that includes imidazoles and oxazoles. Thiazole can also be considered a functional group. They are structurally similar to imidazoles, with the thiazole sulfur replaced by nitrogen. The thiazole rings are planar and aromatic and are characterized by a larger $\pi$-electron delocalization and have therefore great aromaticity [27]. Thiazole derivatives' molecules adsorb probably through the nitrogen or through coordination with surface from the thiazole ring and form the protecting layer. For copper metal, which can form multi-bonds, inhibitor molecules containing such atoms are strongly recommended [28].

To further develop those potential inhibitors it is essential to understand the characteristics and the structure of their metal protective films. Different techniques were utilized for the structural studies of those protective layers. The electrochemical techniques have a great share of such investigations. One of the most applied electrochemical techniques is electrochemical impedance spectroscopy (EIS) [29, 30].

In order to obtain detailed information on the structure and composition of interfaces at the electrode surface, sensitive techniques must be applied. Quartz crystal microbalance (QCM) is one of the very useful techniques applied in the electrochemical field. Electrochemical quartz crystal microbalance (EQCM) is a term for QCM when used in an electrochemical setup.

It consists of piezoelectric quartz, with electrodes on both faces, inserted into a properly designed oscillator circuit. When a voltage is applied between the two faces, the crystal oscillates. The oscillation frequency of a quartz crystal is highly sensitive to the mass supported by the two faces of the device. When one face of the crystal is modified to function as the working electrode, changes of mass and potential of the electrode surface can be continuously monitored $[31,32]$.

EQCM was used as a powerful tool in the interpretation of corrosion and corrosion inhibition mechanisms [33]. The high sensitivity of quartz crystal microbalance is the basis for its application in thin film studies [28, 33, 34].

The aim of this contribution is to investigate the effectiveness of different thiazole derivatives against copper corrosion in sulphate containing acidic solution. The thiazole 
derivatives that will be investigated are: 5-(4-isopropylbenylidene)-2,4-dioxotetrahydro1,3-thiazole (5-IPBDT), 5-benzylidene-2,4-dioxotetrahydro-1,3-thiazole (5-DT), 5-(3'thenylidene)-2,4-dioxotetrahydro-1,3-thiazole (5-TDT), and 5-(3',4'dimetoxybenzylidene)-2,4-dioxotetrahydro-1,3-thiazole (5-MBDT) (Figure 1).

The heterocyclic thiazole molecule<smiles>[R]C=C1SC(=O)NC1=O</smiles>

Inhibitor

$\mathbf{R}$

5-BDT

5-IPBDT
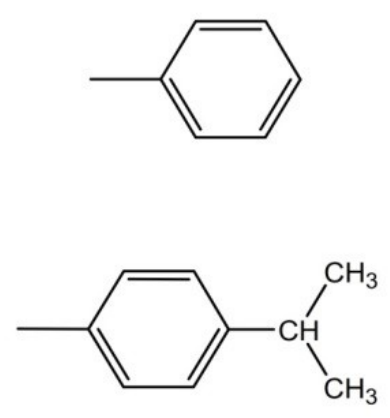

Inhibitor

5-MBDT

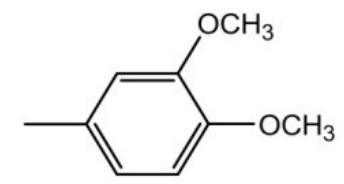

5-TDT
$\mathbf{R}$

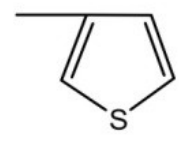

Figure 1. Structure of the investigated thiazole derivatives.

QCM data will consist of both the gravimetrical (mass change vs. time) and the electrochemical (mass and current density change vs. potential). The EQCM data will present the mass change in time and Linear potential scan voltammetric and piezogravimetric characteristics of a fresh thiazole films on a $\mathrm{Cu}-\mathrm{EQCM}$ electrode in $0.1 \mathrm{M} \mathrm{Na}_{2} \mathrm{SO}_{4}+0.01 \mathrm{mmol} / \mathrm{dm}^{3}$ of the thiazole derivatives solution, recorded at a potential scan rate $=1 \mathrm{mV} \cdot \mathrm{s}^{-1}$.

\section{Experimental}

\section{Materials and electrodes}

Galvanostatically deposited copper layers were used for the QCM and EQCM experiments. Reagent grade chemicals (Reanal Finom vegyszergyár) and double distilled water were used to prepare the following electrolytes: $0.1 \mathrm{M} \mathrm{Na}_{2} \mathrm{SO}_{4}$ at $\mathrm{pH} \cong 2.95$, the $\mathrm{pH}$ was adjusted to 2.95 using dilute sulfuric acid.

\section{Investigated chemicals}

The following thiazole derivatives will be investigated at a concentration of $C=$ $0.01 \mathrm{mmol} \cdot \mathrm{dm}^{-3}$ :

- 5-benzylidene-2,4-dioxo tetrahydro-1,3-thiazole (5-BDT) 
- 5-(4'-isopropylbenzylidene)-2,4-dioxotetrahydro-1,3-thiazole (5-IPBDT)

- 5-(3'-thenylidene)-2,4-dioxotetrahydro-1,3-thiazole (5-TDT)

- 5-(3',4'-dimetoxybenzylidene)-2,4-dioxotetrahydro-1,3-thiazole (5-MBDT)

All experiments were done at open atmosphere and room temperature. Due to the low solubility of the tested thiazole derivatives, inhibitors were first dissolved into $20 \mathrm{ml}$ of ethanol and then diluted to the desired concentration. The used optimal inhibitor concentration was determined in previous studies $[19,20]$.

\section{EQCM measurements}

An electrochemical quartz crystal nanobalance Model EQCN-700 (Elchema, Potsdam, $\mathrm{NY}$ ), with a $10 \mathrm{MHz}$ AT-cut quartz resonator, was used in this study. The EQCM technique allowed us for simultaneous monitoring of volt-amperometric $(I$ vs. E) and resonance frequency ( $\Delta f$ or $\Delta m v s . E$ ) versus potential characteristics. For thin rigid films, the interfacial mass changes are related to the changes in oscillation frequency of the EQCM through the Sauerbrey equation [31].

The quartz crystal applied for our investigations had gold layers deposited at both sides (thickness 150-nm) over a thin layer of Cr (thickness $15 \mathrm{~nm}$, for adhesion purpose). Copper layers were galvanostatically electrodeposited on one face of the crystal that's facing the solution, at room temperature. The deposition procedure was described elsewhere [15].

For the QCM measurements, the freshly deposited copper layer was investigated in three time intervals. In the first interval, the deposited $\mathrm{Cu}$ surface was exposed to the corrosive solution $\left(0.1 \mathrm{M} \mathrm{Na}_{2} \mathrm{SO}_{4}\right)$. Then in the second interval, the solution was changed to an inhibitor-containing electrolyte for a longer exposure period. Finally, the solution was changed back to the corrosive electrolyte and the measurement was conducted until most of the deposited $\mathrm{Cu}$ was removed or there was no significant change of the electrode frequency.

The results were obtained in a simultaneous recording of $\Delta m-t$ curves. During all three intervals mass changes were monitored. In the EQCM measurements, freshly deposited $\mathrm{Cu}$ surfaces were deposited as mentioned in the QCM tests. Inhibitors containing solutions were applied and results $(i-E, \Delta m-E)$ were registered after the measuring system stabilized, i.e. there is no change in visco-elastic properties at the interface during measurement. The potential was scanned from -350 to $+100 \mathrm{mV}$ in both a forward and backward scans, at a scan rate of $1 \mathrm{mV} / \mathrm{s}$.

\section{Results and Discussion}

\section{QCM results}

QCM measurements were carried out in $0.1 \mathrm{M} \mathrm{Na}_{2} \mathrm{SO}_{4}$ solution without and with the addition of inhibitors. The adsorption properties of thiazole derivatives were studied and the electrode mass change was monitored in time. 
During the first interval, all experiments showed almost the same behavior. The electrode mass decreased due to copper dissolution (Figure 2). The similar behavior can be explained by the fact that conditions for this interval are the same for all experiments performed. Negligible deviations can be related to difference in surface roughness during $\mathrm{Cu}$ deposition.

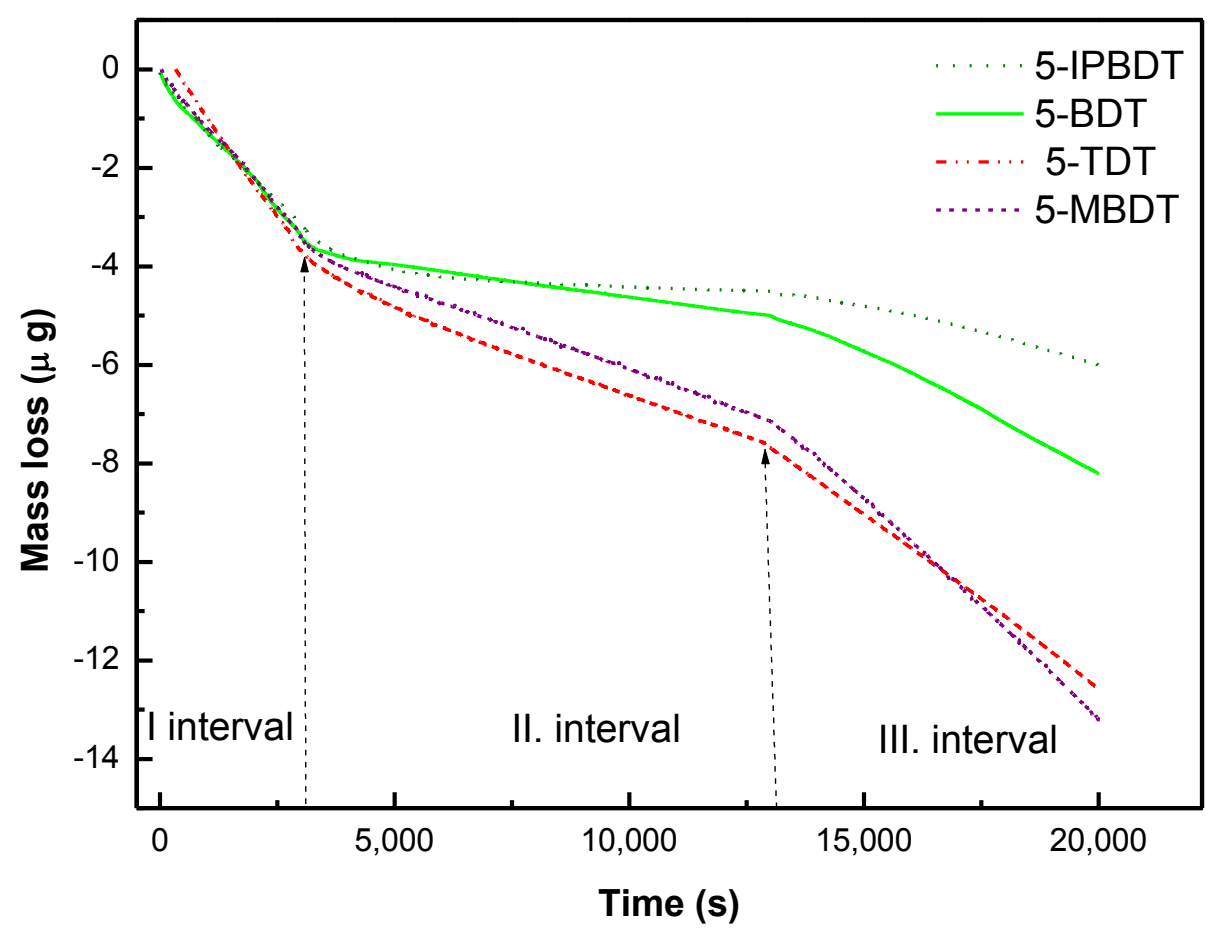

Figure 2. Mass changes of $\mathrm{Cu}$ in acidic $0.1 \mathrm{M} \mathrm{Na}_{2} \mathrm{SO}_{4}$ solution without and with the addition of 5-BDT, 5-IPBDT, 5-TDT and 5-MBDT in time.

The addition of 5-IPBDT and 5-BDT showed significant decreases in the electrode mass change during the second interval. In the third interval, absence of the inhibitor increased the corrosion rate but not as high as in the first interval. This is due to the remaining adsorbed inhibitor molecules or complexes on the electrode surface. 5-IPBDT produced the best protection against copper corrosion, among the tested thiazoles.

To quantify the effect of protection against copper dissolution, the copper electrode thickness reduction rate (TRR) was calculated using Faraday's law, as:

$$
\delta=(\Delta m \cdot 3,600 \cdot 24 \cdot 365 \cdot 10,000) / A \cdot D \cdot t,
$$

where $\delta$ is the thickness reduction rate $[\mu \mathrm{m} / \mathrm{yr}$.]; $\Delta m$ is mass loss; $A$ is electrode surface area $\left(\mathrm{cm}^{2}\right) ; t$ is time $(\mathrm{s}) ; D$ is $\mathrm{Cu}$ density $\left(\mathrm{g} \cdot \mathrm{cm}^{-3}\right)$.

The $\mathrm{Cu}$ electrode thickness reduction rate results, calculated using Eq. 1, and the inhibition efficiencies of the tested thiazoles are tabulated in Table 1. The protection order from the QCM results was in good agreement with other electrochemical measurements [19]. 
Table 1. Thickness reduction rate of $\mathrm{Cu}$ in $0.1 \mathrm{M} \mathrm{Na}_{2} \mathrm{SO}_{4}$ without and with the addition of the thiazole derivatives.

\begin{tabular}{cccccc}
\hline Inhibitor & Blank & 5-IPBDT & 5-BDT & 5-TDT & 5-MBDT \\
\hline $\begin{array}{c}\text { Thickness reduction rate } \\
(\mu \mathrm{m} / \text { yr. })\end{array}$ & 125 & 15 & 18 & 28 & 37 \\
$\begin{array}{c}\text { Efficiency } \\
\eta(\%)\end{array}$ & - & 89 & 86 & 78 & 71 \\
\hline
\end{tabular}

The QCM results showed that the adsorbed layers of the tested inhibitors on the $\mathrm{Cu}$ surface did not grow in time. This result was confirmed by other methods $[19,20]$. The highest inhibition efficiency is provided by the addition of 5-IPBDT $(\approx 90 \%)$. The order of inhibition efficiency for the tested compounds is as follows: $\eta_{5-\text { IPBDT }}>\eta_{5 \text {-BDT }}>\eta_{5 \text {-TDT }}>$ $\eta_{5-M B D T}$.

It is confirmed that even slight change in the molecular structure induces a significant effect on the inhibiting properties of the thiazole molecules. Among the tested thiazole derivatives, 5-IPBDT produced the most efficient protection against copper corrosion in acidic sodium sulfate solution.

The corrosion breakdown potential $\left(E_{\mathrm{b}}\right)$ is one of the most valuable parameters in providing the means for a quick and reliable comparison of the efficiency of various potential corrosion inhibitors. The breakdown potential is not a static parameter and is normally determined under dynamic conditions, usually using a linear potential scan voltammetry. This technique gives us an indication on the onset of anodic current; however, it is not possible to distinguish between the actual metal dissolution and metal oxide scale build-up. Therefore, we applied the EQCM technique and monitored simultaneously the apparent mass variation and current change as a function of potential which was scanned in the anodic direction.

Figure 3 shows piezogravimetric (3a) and voltammetric ( $3 b)$ characteristics of fresh $\mathrm{Cu}$ electrode surfaces in $0.1 \mathrm{M} \mathrm{Na}_{2} \mathrm{SO}_{4}+$ with the addition of $0.01 \mathrm{mmol} . \mathrm{dm}^{-3}$ of the thiazole derivatives solutions, recorded at a scan rate $=1 \mathrm{mV} \cdot \mathrm{s}^{-1}$. The electrode potential was scanned starting from $E=-350 \mathrm{mV}$, to $100 \mathrm{mV}$ and back to $-350 \mathrm{mV}$, vs. SCE. It is seen that the anodic current begins to flow after passing $E=-36 \mathrm{mV}$ in the case of the blank solution. The addition of the thiazole derivatives shifted the break potential to more positive values $\left(E_{\mathrm{b}}=+10 \mathrm{mV}\right.$ for 5 -IPBDT, $+20 \mathrm{mV}$ for 5 -BDT, $+25 \mathrm{mV}$ for 5-MBDT and $-16 \mathrm{mV}$ for 5-TDT) as shown in Table 2.

It is clear, from Table 2, that in the presence of inhibitors, the rate of the mass loss slowed down considerably. In blank solution, when the anodic current started to flow $\left(E_{\mathrm{b}}=\right.$ $-36 \mathrm{mV}$ ), the mass loss was approximately continuous. The mass decrease signifying that the predominant process above the breakdown potential is the copper dissolution from the electrode surface.

The copper dissolution continues up to the anodic reversal potential of $+100 \mathrm{mV}$. On the backwards cathodic scan, further mass decrease is observed. A small reduction peak 
can be seen on $i-E$ curve for the blank solution (Figure 3b). In the presence of the inhibitors, the reduction peak in the cathodic direction scan was not observed; this is also attributed to the strong adsorption of the inhibitor on the $\mathrm{Cu}$ surface.

The copper dissolution continues up to the anodic reversal potential of $+100 \mathrm{mV}$. On the backwards cathodic scan, further mass decrease is observed. A small reduction peak can be seen on $i-E$ curve for the blank solution (Figure $3 \mathrm{~b}$ ). In the presence of the inhibitors, the reduction peak in the cathodic direction scan was not observed; this is also attributed to the strong adsorption of the inhibitor on the $\mathrm{Cu}$ surface.

Table 2. Characteristics of the $\mathrm{Cu}$ electrode immersed in $0.1 \mathrm{M} \mathrm{Na}_{2} \mathrm{SO}_{4}$ without and with the addition of thiazole derivatives at a concentration of $0.01 \mathrm{mmol} \cdot \mathrm{dm}^{-3}$.

\begin{tabular}{ccccc}
\hline $\begin{array}{c}\text { Inhibitor } \\
\text { Solution }\end{array}$ & $\begin{array}{c}\mathbf{E}_{\boldsymbol{b}} \\
(\mathbf{m V})\end{array}$ & $\begin{array}{c}\Delta \mathbf{E} \\
(\mathbf{m V})\end{array}$ & $\begin{array}{c}\Delta \mathbf{m} \\
(\mu \mathbf{g})\end{array}$ & $\begin{array}{c}\mathbf{i}_{\max } \\
\left(\mathbf{m A} / \mathbf{c m}^{2}\right)\end{array}$ \\
\hline $\begin{array}{c}0.1 \mathrm{~mol} \cdot \mathrm{dm}^{-3} \mathrm{Na}_{2} \mathrm{SO}_{4} \\
\text { Blank solution }\end{array}$ & -36 & 0 & -18.5 & 3.27 \\
\hline $\begin{array}{c}0.1 \mathrm{~mol} \cdot \mathrm{dm}^{-3} \mathrm{Na}_{2} \mathrm{SO}_{4} \\
+0.01 \mathrm{mmol} \cdot \mathrm{dm}^{-3} 5-\mathrm{IPBDT}\end{array}$ & +10 & 46 & -6.75 & 1.40 \\
\hline $\begin{array}{c}0.1 \mathrm{~mol} \cdot \mathrm{dm}^{-3} \mathrm{Na}_{2} \mathrm{SO}_{4} \\
+0.01 \mathrm{mmol} \cdot \mathrm{dm}^{-3} 5-\mathrm{BDT}^{-3}\end{array}$ & +20 & 56 & -11.7 & 2.15 \\
\hline $\begin{array}{c}0.1 \mathrm{~mol} \cdot \mathrm{dm}^{-3} \mathrm{Na}_{2} \mathrm{SO}_{4} \\
+0.01 \mathrm{mmol} \cdot \mathrm{dm}^{-3} 5-\mathrm{MBDT}\end{array}$ & +25 & 61 & -11.1 & 2.41 \\
\hline $\begin{array}{c}0.1 \mathrm{~mol} \cdot \mathrm{dm}^{-3} \mathrm{Na}_{2} \mathrm{SO}_{4} \\
+0.01 \mathrm{mmol} \cdot \mathrm{dm}^{-3} 5-\mathrm{TDT}\end{array}$ & -16 & 20 & -14.1 & 2.25 \\
\hline
\end{tabular}

Additionally, in the presence of all inhibitors, copper dissolution started at a more anodic potential than in the blank solution. The shifted corrosion breakdown potential indicates the presence of a compact inhibitor film on copper surface [35].

Among the tested thiazoles derivatives, 5-MBDT produced the highest positive shift of the breaking potential, while 5-IPBDT decreased the mass loss the most. Potential scan rates affect the values of $\mathrm{E}_{b}$ where slower scan rate values increase the $E_{\mathrm{b}}$ values noticeably [34].

It is further seen in Figure $3 b$ that the electrode mass does not return to the initial value in all cases. This is due to either that the starting scan potential should be more negative and/or that a thin layer, of the inhibitors was adsorbed on the surface forming $\mathrm{Cu}$-thiazole layer that hinders the redeposition of the dissolved copper ions. The significantly increased inhibitive property of the 5-IPBDT is a consequence of positive inductive and resonance effects of the isopropyl group, accompanied by hyperconjuction. These effects, are powerful electron-donating, provide increase of the electron density of the active center of thiazole molecules (sulfur atom) and stronger interaction (bonds) between copper and 5-IPBDT molecules beside better protection [36]. 

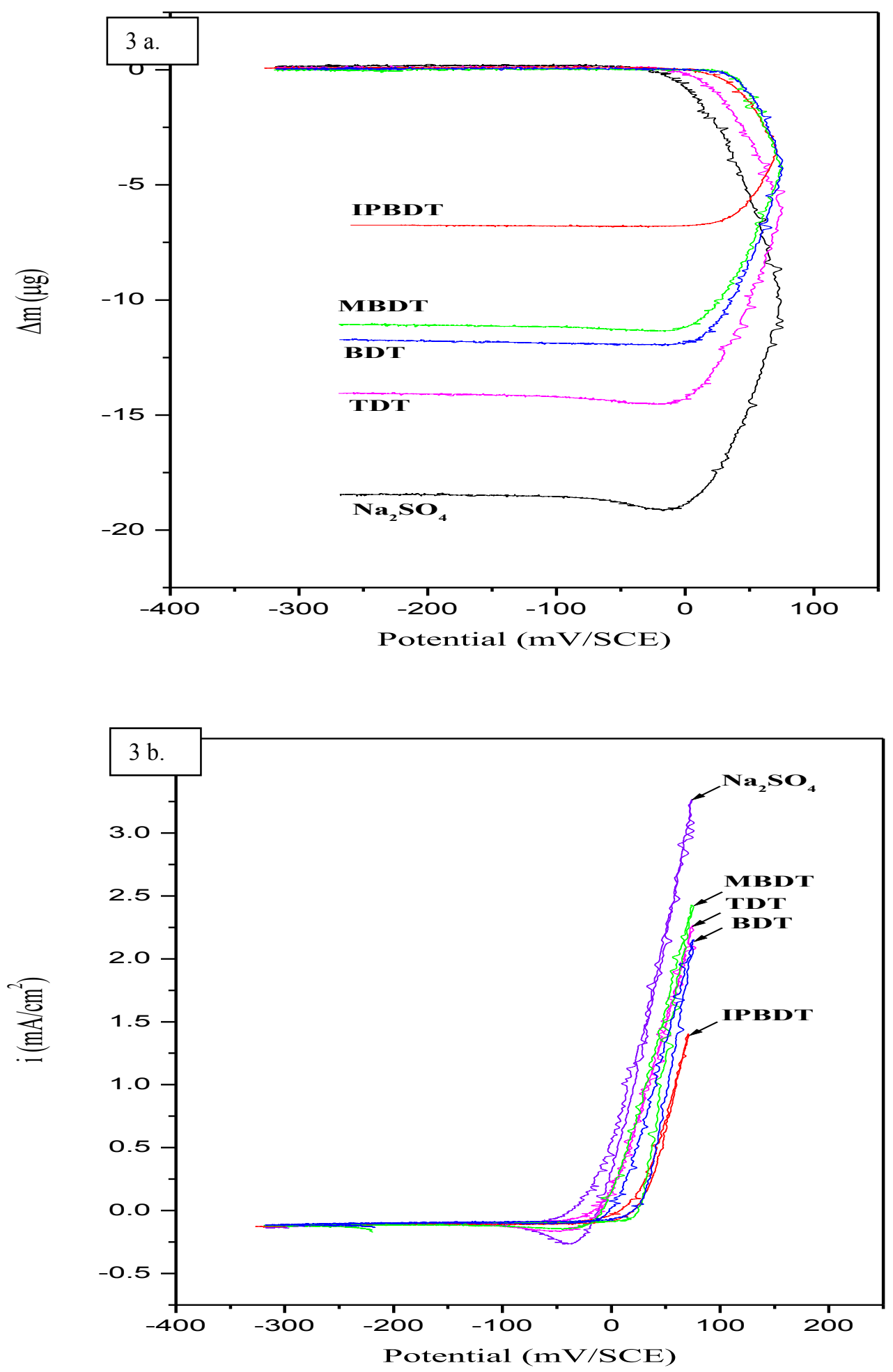

Figure 3. Linear potential scan voltammetric (3a) and piezogravimetric (3b) characteristics of a fresh thiazole films on a $\mathrm{Cu}-\mathrm{EQCM}$ electrode in $0.1 \mathrm{M} \mathrm{Na}_{2} \mathrm{SO}_{4}+0.01 \mathrm{mmol} / \mathrm{dm}^{3}$ of the thiazole derivatives solution, recorded at a scan rate $=1 \mathrm{mV} \mathrm{s}^{-1}$.

In organic chemistry, hyperconjugation is the stabilizing interaction that results from the interaction of the electrons in an s-bond (usually $\mathrm{C}-\mathrm{H}$ or $\mathrm{C}-\mathrm{C}$ ) with an adjacent empty 
(or partially filled) p-orbital or a $\pi$-orbital to give an extended molecular orbital that increases the stability of the system. Hyperconjugation is a factor in explaining why increasing the number of alkyl substituents on a carbocation or radical center leads to an increase in stability. The stabilization arises because the orbital interaction leads to the electrons being in a lower energy orbital [36].

\section{Conclusions}

The inhibition effectiveness of thiazole derivatives was studied using the electrogravimetrical QCM method. The QCM technique provided real time corrosion rate measurements as well as the monitoring of the inhibitor effectiveness. EQCM results showed linear potential scan voltammetric and piezogravimetric characteristics of a fresh thiazole films on a $\mathrm{Cu}$ electrode in $0.1 \mathrm{M} \mathrm{Na}_{2} \mathrm{SO}_{4}$ with the addition of $0.01 \mathrm{mmol} \cdot \mathrm{dm}^{-3}$ of the thiazole derivatives solution. The results performed from these investigations lead to the following conclusions:

- QCM measurements showed that the inhibitor hindered the copper dissolution by forming a protective layer on the copper surface. The inhibitor efficiency of the tested thiazole derivatives reached as high as $89 \%$, as in the case of 5-IPBDT.

- The EQCM results showed that, at a slow scan rate $(1 \mathrm{mV} / \mathrm{s})$ to anodic potential values, in the presence of the thiazoles the copper dissolution decrease was lower than in the blank solution and the breakdown potential was shifted to more positive values $\left(E_{\mathrm{b} \text { inh }}>E_{\mathrm{b} \text { blank }}\right)$.

- The shifted $E_{\mathrm{b}}$ values indicated the presence of compact inhibitor film on copper surface.

- The applied techniques showed that among the tested thiazole derivatives, 5-IPBDT produced the best protection efficiency against copper corrosion in acidic $\mathrm{Na}_{2} \mathrm{SO}_{4}$ solution. This is attributed to the presence of isopropyl group in the 5-IPBDT molecule. Having larger molecule chain can provide umbrella type coverage.

Acknowledgement: These results are the part of project \# OI-172013: "Investigation of synthesis structure and characteristics of natural and synthetic organic compounds", which is supported financially by the Serbian Ministry of Science and Technologies.

\section{References}

1. Ph. Marcus, ed., Corrosion Mechanisms in Theory and Practice, $3^{\text {rd }}$ Ed., CRC Press, 2011.

2. Yu. I. Kuznetsov, M. O. Agafonkina, H. S. Shikhaliev, N. P. Andreeva and A. Yu. Potapov, Int. J. Corros. Scale Inhib., 2014, 3, no. 2, 137. doi: $10.17675 / 2305-$ 6894-2014-3-2-137-148

3. V. Brusic, M. A. Frisch, B. N. Eldridge, F. P. Novak, F. B. Kaufman, B. M. Rush, and G. S. Frankel, J. Electrochem. Soc., 1991, 138, no. 8, 2253.

4. H. Wang, Q. Wu, C. M. Li and N. Gu, Mater. Corros., 2013, 64, no. 4, 347. 
5. Yu. I. Kuznetsov, Int. J. Corros. Scale Inhib., 2012, 1, no. 1, 3. doi: $\underline{10.17675 / 2305-}$ 6894-2012-1-1-003-015

6. A. Jardy, A. Lasalle-Molin, M. Keddam and H. Takenouti, Electrochim. Acta, 1993, 37, 2195.

7. M. Antonijevic and M. Petrovic, Int. J. Electrochem. Sci., 2008, 3, 1.

8. J. Uehara, H. Nishihara and K. Aramaki, J. Electrochem. Soc., 1990, 137, 2677.

9. J. Uehara and K. Aramaki, J. Electrochem. Soc., 1991, 138, 3245.

10. M. Itoh, H. Nishihara and K. Aramaki, J. Electrochem. Soc., 1994, 141, 2018.

11. M. Itoh, H. Nishihara and K. Aramaki, J. Electrochem. Soc., 1995, 142, 1839.

12. Y. Yamamoto, H. Nishihara and K. Aramaki, J. Electrochem. Soc., 1993, 140, 436.

13. M. Finšgar and I. Milošev, Corros. Sci., 2010, 52, 2737.

14. N. Ohno, J. Uehara and K. Aramaki, J. Electrochem. Soc., 1993, 140, 2512.

15. E. Szőcs, Gy. Vastag, A. Shaban, G. Konczos and E. Kálmán, J. Appl. Electrochem., 1999, 29, 1339.

16. E. Sherif and S. Park, Electrochim. Acta, 2006, 51, 4665.

17. E. Sherif and S. Park, Electrochim. Acta, 2006, 51, 6556.

18. F. Zucchi, G. Trabanelli and M. Fonsati, Corros. Sci., 1996, 38, 2019.

19. Gy. Vastag, E. Szöcs, A. Shaban and E. Kálmán, Pure Appl. Chem., 2001, 73, 1861.

20. Gy. Vastag, E. Szőcs, A. Shaban, I. Bertóti, K. Popov-Pergal and E. Kálmán, Solid State Ionics, 2001, 141-142, 87.

21. M. Antonijevic, S. Milic, S. Šerbula and G. Bogdanovic, Electrochim. Acta, 2005, 50, 3693.

22. D. Zhang, L. X. Gao and G. Zhou, Appl. Surf. Sci., 2004, 225, 287.

23. E. Skrypnikova, S. Kaluzhina and L. Agafonova, Int. J. Corros. Scale Inhib., 2014, 3, no. 1, 59. doi: $10.17675 / 2305-6894-2014-3-1-059-065$

24. E. Szőcs, Gy.Vastag, A. Shaban and E. Kálmán, Corros. Sci., 2005, 47, 893.

25. A. Lalitha, S. Armes and S. Rajeswari, Electrochim. Acta, 2005, 51, 47.

26. H. Otmacic and E. Lisac, Electrochim. Acta, 2003, 48, 985.

27. Wikipedia the free Encyclopedia: http://en.wikipedia.org/wiki/Thiazole.

28. J. Telegdi, A. Shaban and E. Kálmán, Electrochim. Acta, 2000, 45, no. 22-23, 3639.

29. N. Huynh, S. Bottle, T. Notoya and D. Schweinsberg, Corros. Sci., 2002, 44, 2583.

30. F. Bayoumi, A. Abdullah and B. Attia, Mater. Corros., 2008, 59, 691.

31. G. Sauerbrey, Z. Phys., 1959, 155, 206.

32. S. Bruckenstein and M. Shay, Electrochim. Acta, 1985, 30, 295.

33. M. Fonsati, F. Zucchi and G. Trabanelli, Electrochim. Acta., 1998, 44, 311.

34. M. Hepel and E. Cateforis, Electrochim. Acta., 2001, 46, 3801.

35. D. Kouznetsov, A. Sugier, F. Ropital and C. Fiaud, Electrochim. Acta, 1995, 40, 1513.

36. F. Carey, Organic Chemistry, McGraw-Hill Companies, $7^{\text {th }}$ ed., 2007. 